\title{
SYNERGIES BETWEEN ENVIRONMENTAL PRESSURES IN THE URBAN CLIMATE: COMBINED AIR QUALITY AND NOISE EXPOSURE ASSESSMENT IN THESSALONIKI, GREECE
}

\author{
VLACHOKOSTAS Ch. * \\ MICHAILIDOU A.V. \\ ATHANASIADIS A. \\ MOUSSIOPOULOS N.
}

\author{
Laboratory of Heat Transfer and Environmental Engineering \\ Department of Mechanical Engineering \\ Aristotle University of Thessaloniki \\ 54124 Thessaloniki, Greece
}

Received: 07/04/13

Accepted: 16/05/13 *to whom all correspondence should be addressed: e-mail: vlahoco@aix.meng.auth.gr

\begin{abstract}
This study offers a combined analysis of personal exposure to noise and air pollution within the metropolitan centre of Thessaloniki, Greece. The area is selected on the grounds that it is considered as one of the most polluted cities in Europe, especially with respect to air pollution. An extensive survey has been designed to provide detailed information on $\mathrm{CO}$ and VOC concentrations and noise pollution levels in the main modes of transport and along heavy traffic routes inside the core of the urban area under consideration. Air pollution and noise measurements were performed simultaneously along several commuting routes, during morning and evening rush hours. Personal portable devices were used. The results highlight the magnitude of air and noise urban scale personal exposure, since they depict a considerable environmental burden for the citizens of Thessaloniki, especially for VOCs and noise pollution levels. Furthermore, they provide, for the first time, a combined exposure assessment to these environmental pollutants for Thessaloniki and in this sense they are of importance for local public authorities and decision makers. The material herein points out the importance of micro-environmental monitoring and the necessity of considering environmental pollution in urban areas in a more holistic way.
\end{abstract}

KEYWORDS: Combined exposure assessment; Air pollution; Noise pollution; health stressors; Thessaloniki, Greece.

\section{INTRODUCTION}

In terms of environmental aspects, urban areas are of great importance. This is because they are often characterised by high levels of air pollution, mainly traffic-related, while they simultaneously present high population density. It is widely acknowledged between public health experts that air pollution may aggravate morbidity (especially respiratory, cardiovascular and neurological diseases and degenerations) and may also lead to premature mortality (e.g. Pope et al., 2011; Katsouyanni et al., 2001). Thus, over the past decades, there has been increasing concern regarding air quality in urban centres. In most European city centres, the corresponding activities of the population and especially road traffic, is considered to be the most important emission source of local air pollutants, which can cause adverse effects on health and the environment (HEI, 2010). Health effects of traffic generated air pollution can possibly be attributed to a complex mixture of species from road traffic. It is impossible to measure all relevant components, due to practical and economic constraints, especially in this period of economic crisis (i.e. lack of suitable technologies, logistical difficulties inevitably involved etc). However, all stressors in the atmospheric mixture are not necessarily of the same concern to health. The usual adopted approach is the selection of a traffic-related marker, such as particulate matter (PM) or a typical gaseous air pollutant, used for a variety of applications e.g. source apportionment, air quality management, human exposure assessment and epidemiological studies. It is well established that Nitrogen Oxides $\left(\mathrm{NO}_{\mathrm{x}}\right)$ and/or Carbon Monoxide 
(CO) are more often used as markers for traffic-related air pollution. However, traffic exhaust emits considerable amounts of Volatile Organic Compounds (VOCs), such as aromatic compounds (Benzene, Toluene, Ethylbenzene and Xylene (BTEX), or alkanes and alkenes). In addition, the concentration of benzo[a]pyrene -a marker for the concentration of Polycyclic Aromatic Hydrocarbons (PAHs) in ambient air- is an indicator of the influence of traffic on air quality in locations where the impact of other sources (e.g. wood burning) is negligible (WHO, 2005). Probably there are more chemical health stressors in the atmospheric mixture that scientific research has not put forward, at least up to now. The scientific gap and the inherent epidemiological uncertainties can be characterised as significant the least, especially when considering combined or synergetic human exposure to the complex air pollution mix.

On top of being exposed to chemical stressors, excessive human exposure to physical stressors such as high levels of environmental noise, may also pose a serious threat to public health. In urban centres, environmental noise can be mainly attributed to road traffic, mainly engine sound and/or rolling sound, caused by the friction of tyres on the road surface. Excessive human exposure to noise is associated with a wide variety of malign effects, ranging from mild discomfort and annoyance to depression, ultimately resulting in reduced quality of life (e.g. Murphy et al., 2009). Furthermore, excessive human exposure to noise may act as a synergetic factor, thus increasing the risk of heart disease in middle-aged men (Babisch et al., 2005). According to estimations, $20 \%$ of European Union's (EU) population is exposed to detrimental levels of environmental noise (King et al., 2009).

In this context, citizens within urban areas are exposed to harmful environmental pollutants in a synergistic way. Provided that noise and air pollution are taken in combination, they represent a significant environmental hazard to public health. This paper presents a combined environmental pollution exposure assessment, based on measurements from personal portable monitors conducted in Thessaloniki's urban core. An extensive field campaign has been designed in order to provide detailed information on VOCs, $\mathrm{CO}$ and noise pollution levels in the main transport modes and along heavy traffic routes in the Thessaloniki city centre. Up to the authors' knowledge, no comprehensive study of combined human exposure assessment has been carried out in the Thessaloniki area.

An urban space and/or microenvironment needs to be characterised regarding its air quality since human exposure is meaningful in spaces that present a high density of receptors. Hence, densely populated or usually crowded places are of significant importance. And that is because on the one hand, citizens spend a substantial amount of their time in spaces where human exposure levels to environmental stressors are often highly elevated, while on the other hand, their corresponding activities may often induce emission of hazardous environmental stressors. The space of interest may be a closed environment such as the interior of a car or an open-air environment such the saddle of a bike or a motorcycle. As a result, the exposed individuals may range from commuters, such as drivers and pedestrians, to people working along busy streets or even residents in such areas (Vlachokostas et al., 2013). In our case, four modes of transport are under consideration which account for approximately $75 \%$ of commuting activity in the Thessaloniki City region (ORTH, 2008).

An integrated personal exposure assessment methodological framework is followed in order to characterise urban microenvironments. In contrast to the majority of the currently employed methodologies, the presented approach enables the evaluation of the human exposure assessment in terms of air and noise pollution combined impact on citizens. The proposed approach is based on seven discrete methodological steps: (i) Selection of study area, (ii) Selection of measuring periods, (iii) Selection of personal mobile equipment, (iv) Selection of transport means, (v) The measurement campaign, (vi) Data post-processing, (vii) Microenvironment's characterisation and personal exposure assessment.

\section{CASE STUDY}

\section{Site description}

Thessaloniki was chosen for this study, due to some specific characteristics that the city presents. It is the second largest Greek city, co-capital of Greece and capital of the region of Central Macedonia. It is located in northern Greece, and is surrounded by the Thermaic gulf and mount Chortiatis, thus combining the characteristics of coastal and mountainous areas. It is one of the largest and most 
populated cities in the Balkan region and a major economic, industrial, commercial and political centre. It serves as a major transportation hub for the rest of the south-eastern Europe due its geopolitical position. Poor urban planning along with lack of routine measurements, intensify the problem of vehicle and industrial emissions in the Greater Thessaloniki Area (GTA) (Figure 1).

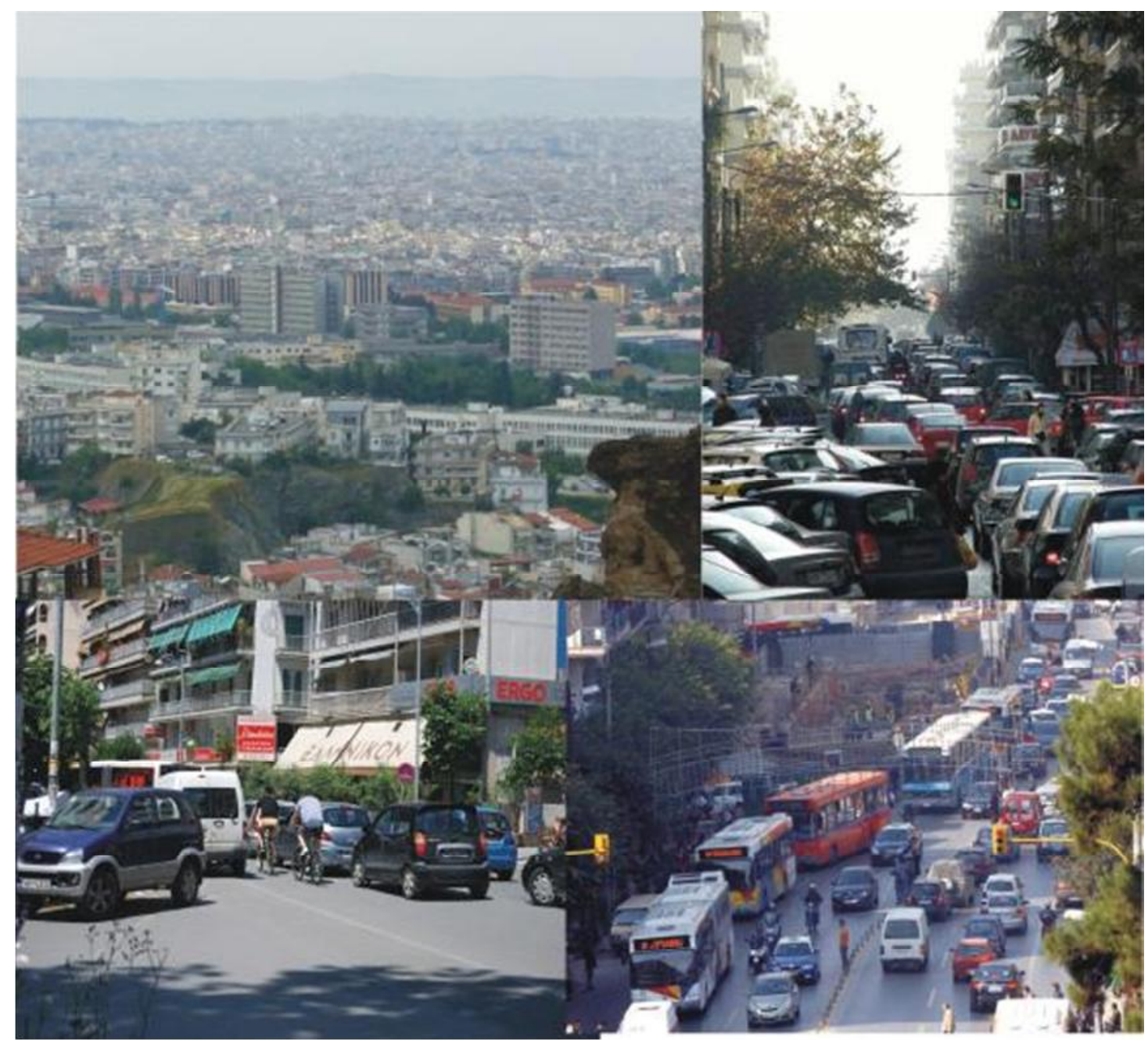

Figure 1. Poor urban planning and traffic activity in the metropolitan centre of Thessaloniki

Figure 1 depicts problems such as the density of urban built environment (upper left), saturated traffic in street canyon such as Pavlou Mela street (upper right), the difficulty of the bicyclists to move in the city (lower left) and the bad timing of the city busses in the corresponding bus lanes (lower right). Environmental problems, air pollution dynamics and the interannual trend of monitored pollutants of the area under consideration are analytically described in Moussiopoulos et al. (2009, 2010).

The vast majority of the population is concentrated in and around the city's centre, where motor vehicle emission is by far, the main contributor in air pollution (Vlachokostas et al., 2009). Traffic activity which has reached extremely high levels is a result of problematic street planning and a poor public transportation system (ORTH, 2008). Therefore, citizens that live, work, commute or spend substantial time in areas with heavy traffic, are exposed to high levels of traffic-related pollution (Kassomenos et al., 2011). Furthermore, the urban city centre suffers from high levels of trafficrelated noise. However, despite the fact that noise is a common problem among large Greek cities, there is sparse information in actual noise levels in streets (Kelessis et al., 2008; Tzekakis et al., 2005; Georgiadou et al., 2004). The available measurements display that the traffic noise in the central road network of Thessaloniki exceeds the national and EU limits. Taking the above into consideration, four routes were designed in order to assess human exposure to environmental 
stressors in the city core (Figure 2). The routes represent typical commuting trips for the population operating throughout the metropolitan centre.

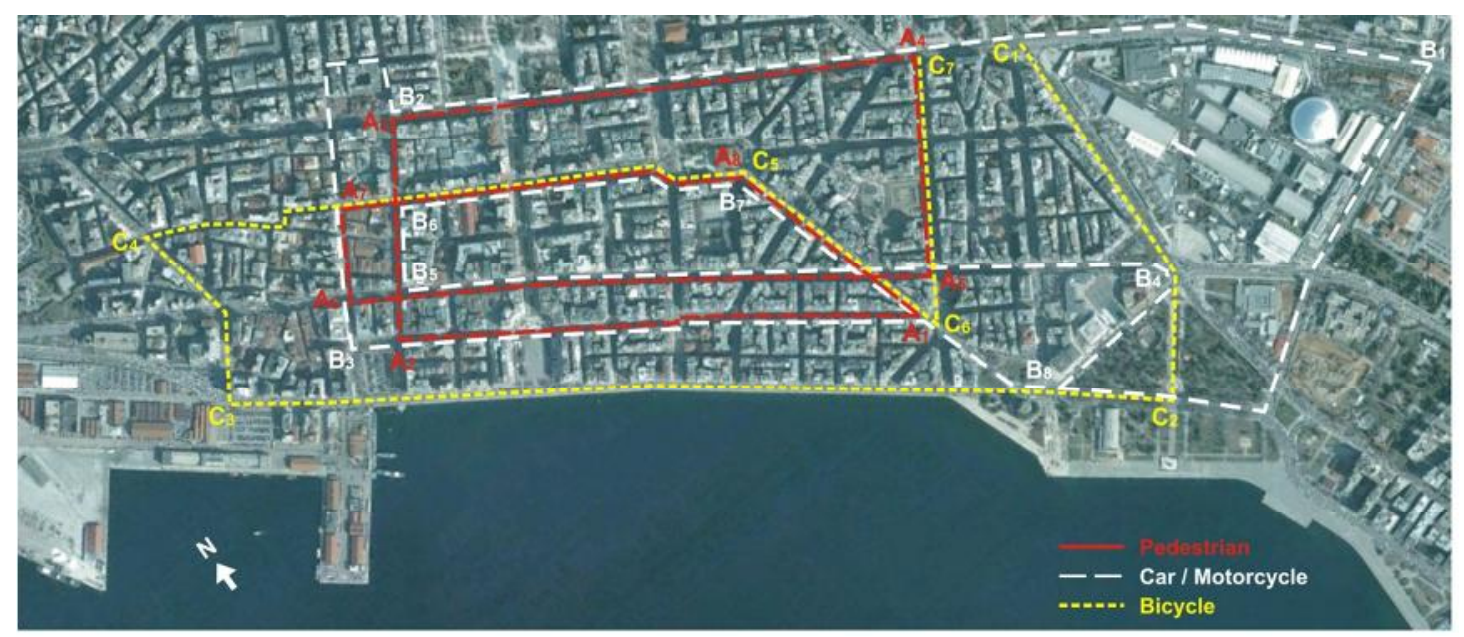

Figure 2. The standard routes chosen for the city centre of Thessaloniki

\section{Study design and sampling}

In the context of this case study, an extensive survey was specially designed, in order to provide detailed information about outdoor levels of specific chemical and physical stressors. Pollution levels for $\mathrm{CO}$, VOCs and noise were measured for the main transport modes commuting through the specific routes mentioned above. The field measurements were conducted in order to record pedestrian, on-bicycle, on-motorcycle and in-car concentrations for the above chemical and physical stressors. The measurements cover the morning and evening rush hours (09:00-11:00 and 19:0021:00, respectively) over a period of 12 months (from March, 2010 to February, 2011), in an attempt to capture human exposure, when peaks of traffic pollution are accompanied with peaks in receptor density. Additional sampling was performed for two random weeks per month, using seven different starting points per week (Figure 2), in an attempt to overcome the spatial and temporal variability.

The measuring equipment used for the field campaign was a portable, electrochemical $\mathrm{CO}$ and VOCs monitor with Photo lonisation Detection (PID) technology (Ion Science's FirstCheck 5000+) and a portable sound $\left(\mathrm{L}_{\mathrm{eq}}\right)$ level meter and datalogger (Extech's HD 600) (Figure 3). Both instruments are compact, light and calibrated according to the manufacturers' instructions. Additional meteorological data were obtained from a local weather station located in the centre of the area of interest.
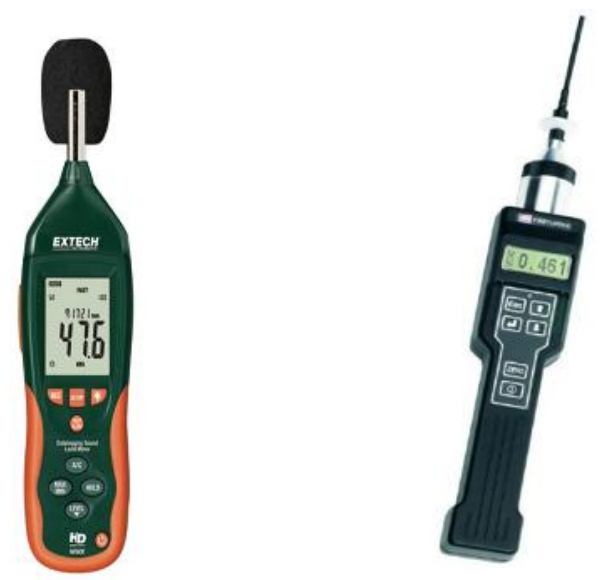

Figure 3. Portable equipment used in the presented study.

FirstCheck 5000+ for VOCs/CO (left) and Extech's HD 600 for noise levels (right).

During the pedestrian sampling on the sidewalks, the CO/VOCs monitor was carried in a small backpack with the sampling inlet placed at the breathing zone, while the portable sound level meter 
was fixed to the waist of the volunteers facing the free air stream. Average walking duration was 8090 minutes for the $5.3 \mathrm{~km}$ route shown in Figure 2. For in-car sampling, the equipment was placed at the passenger seat of the sampling car (Opel Corsa, 1200cc, 2005 model), parallel to the breathing zone of the driver. In order to improve the representativeness of the measurements, the sampling was conducted with both open and closed windows, while the ventilation system was on. Mean driving time was 35 minutes for the $8.4 \mathrm{~km}$ route shown in Figure 2. For motorcycle sampling (Kymco Spike, $125 \mathrm{cc}$ ) the average time for the same route as that of the car was 25 minutes. The bicycle travelled 20 minutes on average, for the route shown in figure 2 , mostly using the cycling lanes (where available) or the area next to the sidewalks (frequently on the bus lanes). The placement of the equipment is described above. More information about this measuring campaign can be found in Vlachokostas et al. (2012).

\section{RESULTS}

The inter-mode average human exposure levels to the various environmental health stressors for the morning and evening sampling periods are presented in Figure 4. During both sampling periods and especially in the morning, the motorcyclist is exposed to higher levels of the gaseous pollutants (CO and VOCs), followed by the car driver. More specifically, average exposure concentration levels experienced on the motorcyclist were 2 to 3 times higher than those on the car passenger. The motorcyclists reported that they felt exhaust gases, but also motorcycle petrol fumes in their breathing zone in "rev-up" conditions. This is most probably the reason for an annual average VOC exposure level of approximately $300 \mathrm{ppb}$ compared to $100 \mathrm{ppb}$ in-vehicle pollution ( 3 to 1 relation). Contrariwise, the bicyclist and the pedestrian are exposed the least. This is mainly due to the fact that cars and motorcycles are closer to vehicle exhausts than bicyclists and pedestrians. It should be noted that the corresponding car driver/pedestrian analogy approximates 2 to 1 relation both for VOCs and CO. Moreover, the estimated motorcycle/bicycle analogy approximates 10 to 1 relation for VOCs (Figure 4). Human exposure to traffic noise did not present significant differences among modes and was almost independent of the time of day. Motorcycle users are exposed to the highest levels of noise pollution, mainly due to the motorcycle's motor background noise.

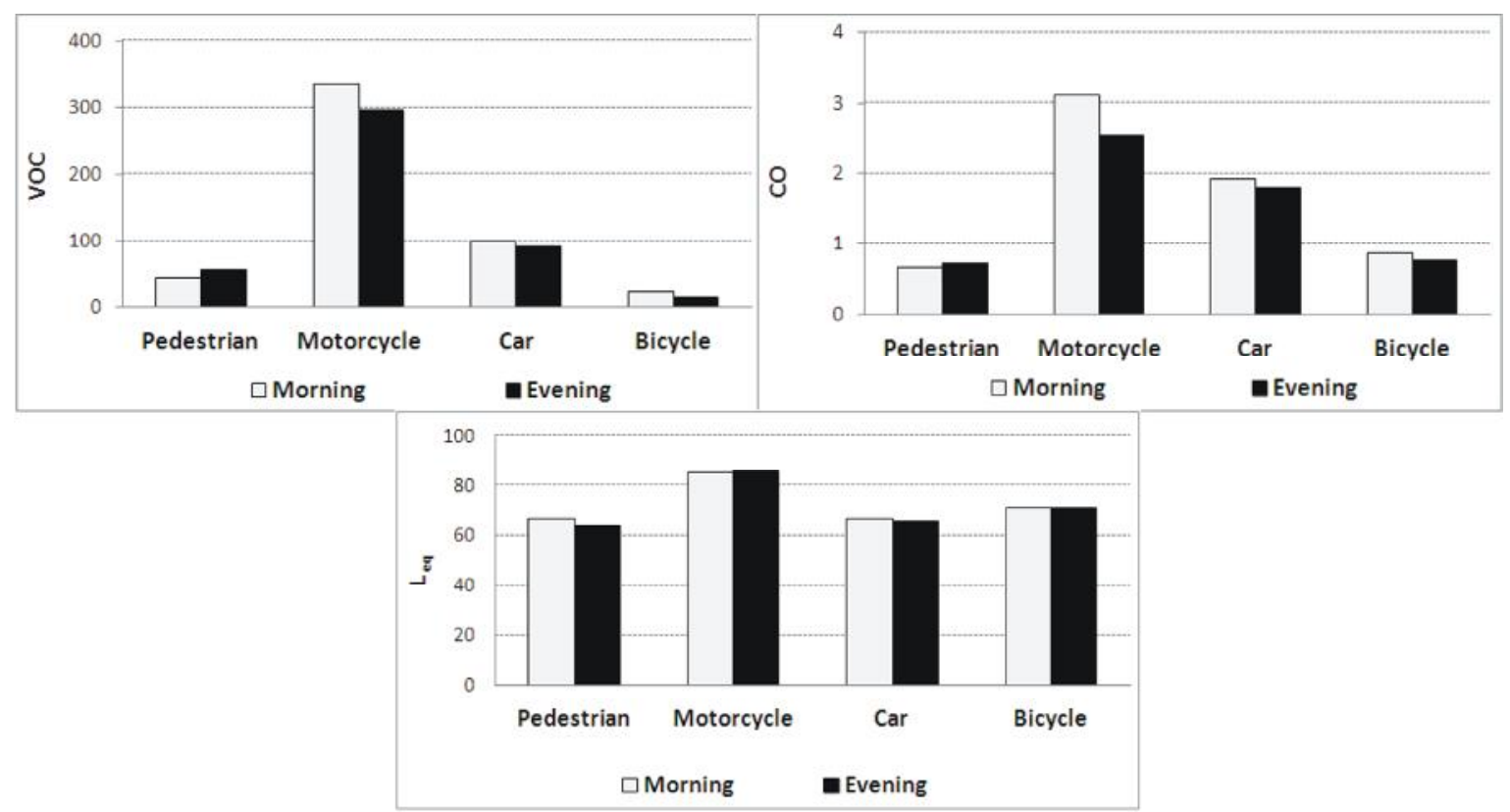

Figure 4. Inter-mode human exposure levels to VOCs (ppb), $C O(p p m)$ and noise $(\mathrm{dB}(\mathrm{A}))$

The intra-mode variation among different routes presents significant variability. In all studied routes and microenvironments, the bicyclist and the pedestrian are exposed to significantly lower levels of $\mathrm{CO}$ and VOCs. That's not the case for the motorcyclist who is exposed to the highest levels of air pollution, followed by the car driver (Figures 5 and 6 ). In general, the busiest and trafficked the route is, the higher the human exposure is. Thus, the route along Tsimiski street, with an average daily traffic volume of about 50,000 units, present high maximum 1-min average for $\mathrm{VOC} / \mathrm{CO}$ concentrations i.e. up to $0.9 / 11.1 \mathrm{ppm}$ for pedestrian, $1.2 / 61.1$ for car driver and 5.1/80.4 ppm for 
motorcycle. Likewise, the route along Egnatia street present high maximum 1-min average for $\mathrm{VOC} / \mathrm{CO}$ concentrations i.e. up to $1.1 / 5.2 \mathrm{ppm}$ for pedestrian, 1.1/14 for car driver and 3.4/46.3 ppm for motorcycle. However, the routes through Pavlou Mela and Dragoumi streets, present the highest human exposure levels, even though the average daily traffic volumes are around 5 times lower than the ones of Egnatia and Tsimiski streets (Figures 5 and 6). The latter can be attributed to the specific geometry of these particular routes and the meteorological conditions, especially wind direction and speed on the site. Both streets are relatively narrow, when compared to the buildings on each side, while the prevailing wind direction is not on the street axis $\left(45^{\circ}-90^{\circ}\right)$. As a result, street canyon vortexes are likely to appear, enhancing recirculation inside the street canyon, preventing the dispersion of pollutants, thus resulting in increased concentrations, especially in the sidewalk areas. The routes through Ermou, Venizelou and Mitropoleos streets, with average traffic volumes of about 10,000 units each, present similar human exposure levels with Dragoumi and Pavlou Mela streets. Conclusively, while traffic density seems to be the most important factor when examining air quality in urban areas, one can't overlook the importance of the geometry and meteorology of a microenvironment. Therefore, these two factors should be carefully considered for urban planning and sustainability issues. In the case of the route through Gounari street, which belongs to a pedestrian zone, there is a significant improvement in the air quality (Figures 5 and 6).

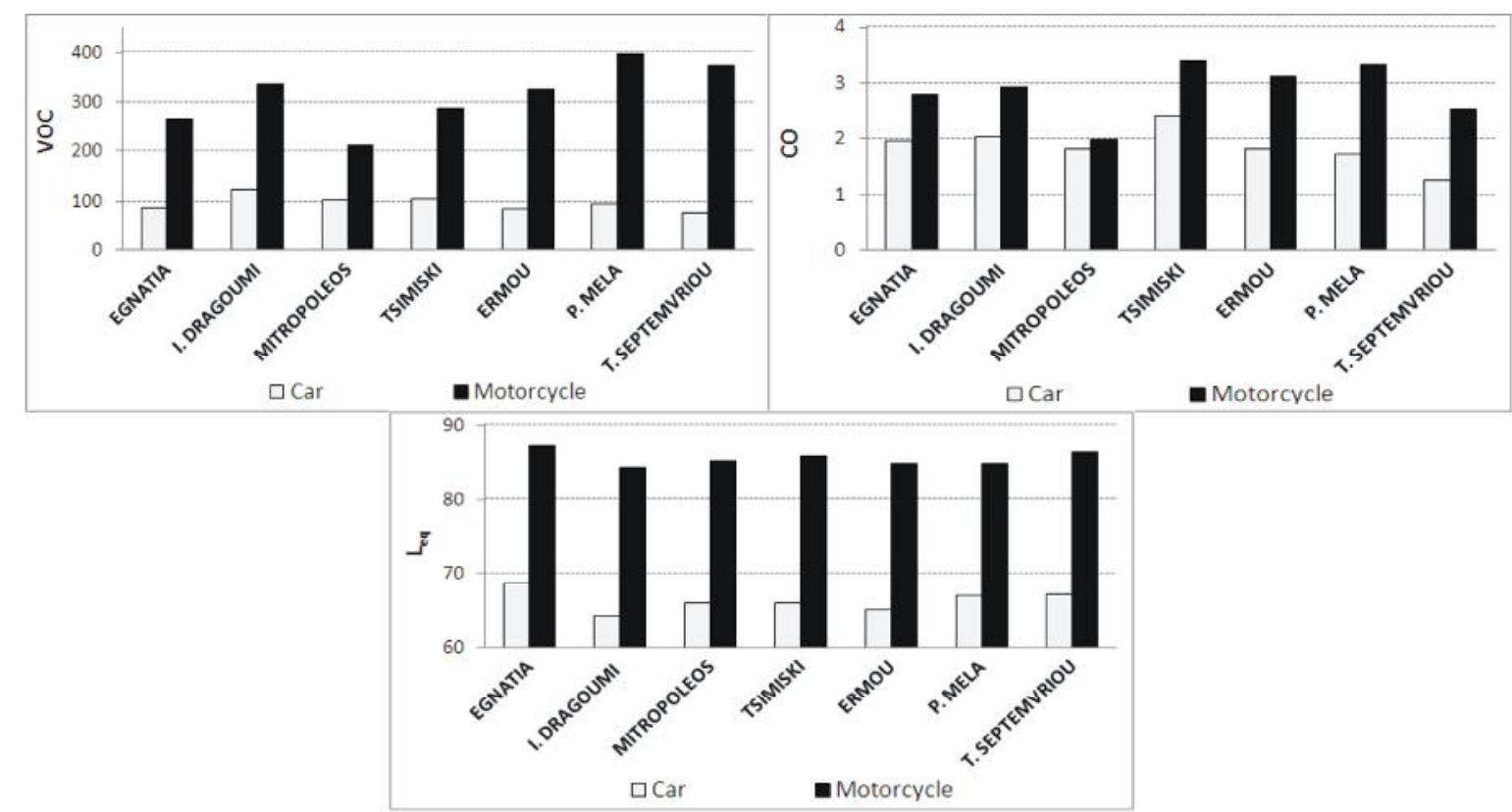

Figure 5. Human exposure to environmental stressors: VOC (ppb) upper left, $\mathrm{CO}(\mathrm{ppm})$ upper right and noise $(\mathrm{dB}(\mathrm{A}))$ bottom, for various routes (Car and Motorcycle)

Nevertheless, noise pollution does not follow the aforementioned pattern (Figure 5 and 6 ). This is due to various pedestrian activities, and to the motorcyclists that (ab)use the pedestrian street. Noise invehicle levels with both front windows open are lower than those of the pedestrian, though quite significant. Motorcyclists suffer considerable noise burden, which is over $80 \mathrm{~dB}(\mathrm{~A})$, which adds its motor noise (background $66 \mathrm{~dB}(\mathrm{~A})$ for idle speed conditions). Traffic conditions influence significantly motorcycle's speed and consequently its motor noise, e.g. a not trafficked uphill road produces significantly more engine noise than the ambient to the motorcyclist, due to "rev-up" driving conditions. However, high exposure air pollution levels are attributed to factors such as ventilation and the low-lying position of the vehicle which is susceptible to the intake of the emissions of the vehicle in front.

Another important aspect of human exposure to environmental stressors is their inter-seasonal variation, especially when viewed in conjunction with meteorological variables, namely wind speed. Chemical stressors' levels are highly dependent on meteorological conditions prevailing in microenvironments, and far more complex to study. And that's because the various chemicals are subject to several phenomena such as dispersion and dilution. Furthermore, chemicals often take part in various photochemical transformations, forming secondary pollutants. VOCs and CO levels are 
significantly lower in summer, when compared to winter and autumn possibly due to higher wind speeds and photochemistry reasons. It should be noted that the majority of the local population and tourists are concentrated within and adjacent to the city centre i.e. many citizens who live, work, commute, shop or visit for recreation purposes areas and microenvironments exposed to heavy traffic throughout the whole year. Thus, it is not surprising that the noise levels for the four different seasons of the year, do not present any significant variability.

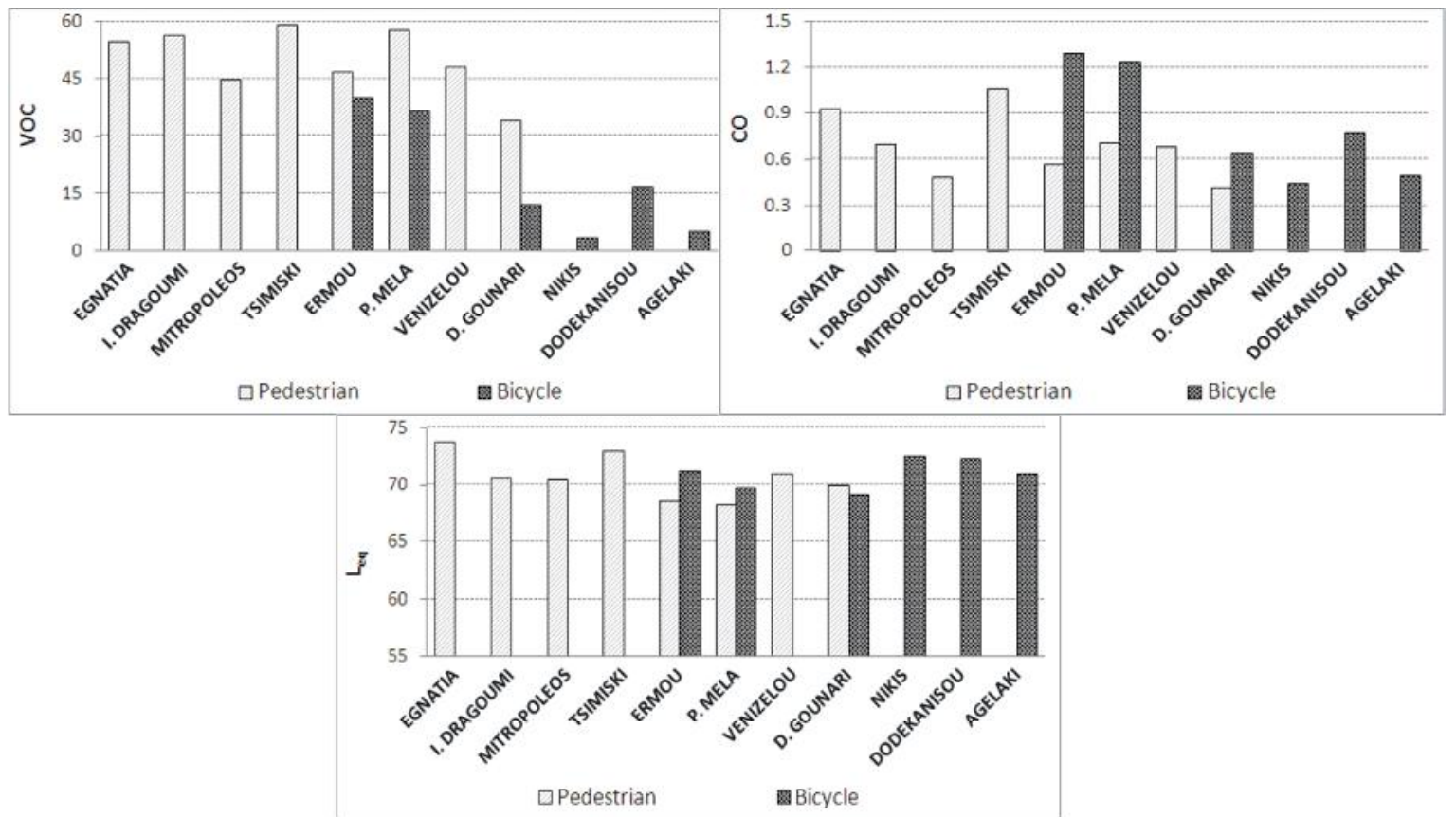

Figure 6. Human exposure to environmental stressors VOC $(\mathrm{ppb})$ upper left, $\mathrm{CO}(\mathrm{ppm})$ upper right and noise $(\mathrm{dB}(\mathrm{A}))$ bottom, for various routes (Pedestrian and Bicycle)
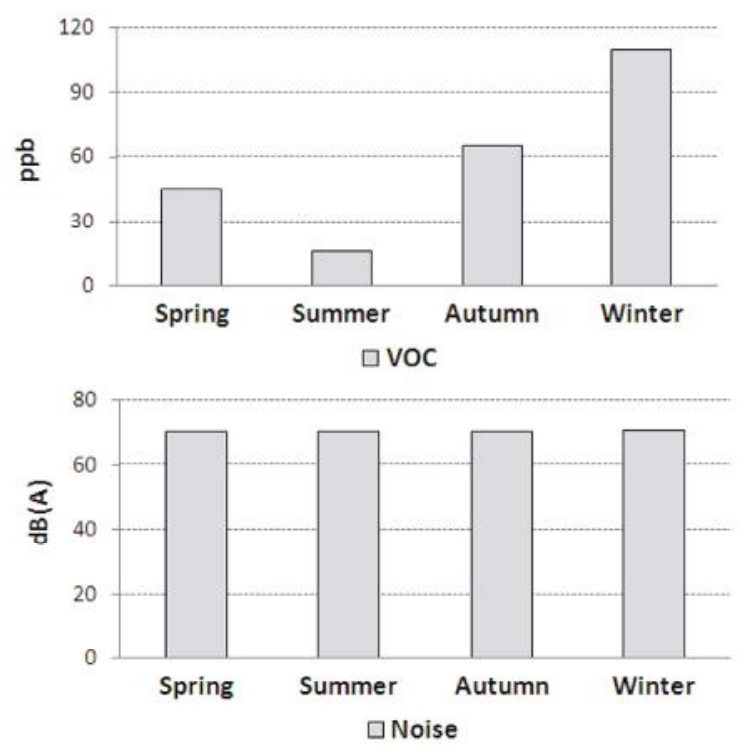
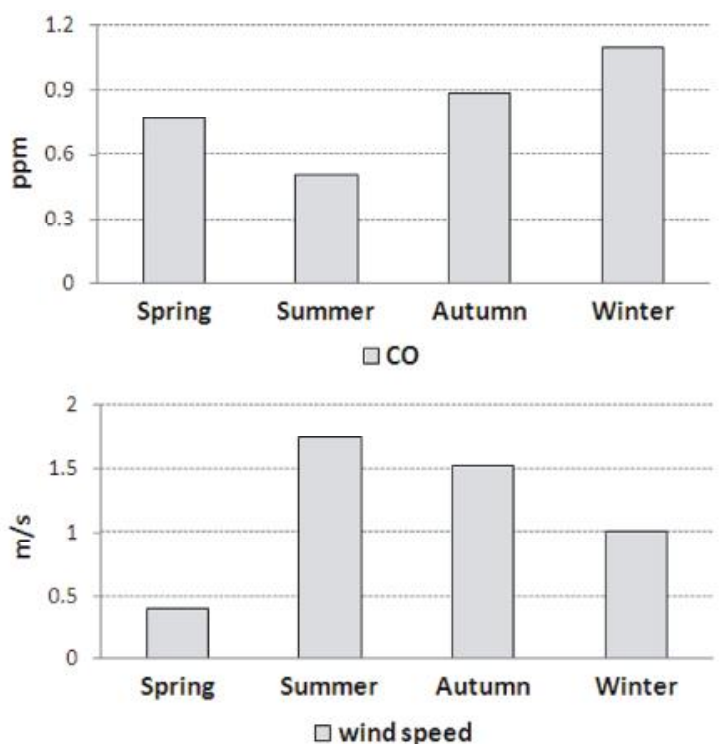

Figure 7. Inter-seasonal variation of pollutant levels and wind speed for the pedestrian exposure assessment

\section{CONCLUSIONS}

The presented analysis evaluates variations in personal exposure between transport modes, routes, seasons and timings, and examines human exposure levels in the transport microenvironments of the area's urban core. Factors such as the mode of transport selected, the microenvironments of every route, the season of the year and the corresponding meteorological conditions, seem to have a significant effect on air and noise pollution burden. Commuters experience the highest 
combined/synergistic levels on the most heavily trafficked and congested routes. Modes of transport along the direct release zone of atmospheric and noise pollution, i.e. the motorcycle and the passenger car, present higher exposure compared to average exposure levels of adjacent or on pavement modes, such as the bicyclist and the pedestrian exposure. However, the car commuter sits in a state of rest. It should be considered that more physically exerting modes of transport could be as highly impacted as the car commuter's health (Vlachokostas et al., 2012).

Moreover, a more comprehensive comparison could have been made if all modes were sampled simultaneously for all environmental pollutants under consideration, but this was not logistically feasible in the framework of this analysis, even for two modes with the same route. Last but not least, it should be noted that exposure to environmental stressors, especially in urban areas, should be examined in a holistic manner. The various stressors interact with each other, often with a synergetic manner, and are highly dependent to citizen activity and meteorological variables. As a result, the need of careful and routine monitoring, in order to assure abundance of data for the urban climate, should be stressed out. As a final statement, one issue should be emphasised. Environmental pressures present a dynamic character. It is important to recognise that continued coordination and integration among environmental scientists, local policy-makers and politicians is of vital importance in order to optimise successful progress of any air pollution control effort (Vlachokostas et al., 2011).

\section{REFERENCES}

Babisch W., Beule B., Schust M., Kersten N. and Ising H. (2005), Traffic noise and risk of myocardial infarction, Epidemiology, 16, 33-40.

Georgiadou E., Kourtidis K. and Ziomas I. (2004), Exploratory traffic noise measurements at five main streets of Thessaloniki, Greece, Global Nest: the Int. J., 6, 1, 53-61.

HEI Panel on the health effects of Traffic-Related Air Pollution (2010), Traffic-Related Air Pollution: A Critical Review of the Literature on Emissions, Exposure, and Health Effects Special Report 17. Health Effects Institute, Boston, MA.

Kassomenos P.A., Kelessis A., Paschalidou A.K., and Petrakakis M. (2011), Identification of sources and processes affecting particulate pollution in Thessaloniki, Greece, Atmos. Environ, 45, 7293-7300

Katsouyanni K, Touloumi G, Samoli E, Gryparis A, Le Tertre A, Monopolis Y, et al. (2001), Confounding and effect modification in the short term effects of ambient particles on total mortality: results from 29 European cities within the APHEA2 project, Epidemiology, 12, 521-531.

Kelessis A.G., Tzoumaka P.N. et al. (2008), The traffic noise levels at the city centre and the eastern region of Thessaloniki, Greece, Proceedings of the $3^{\text {rd }}$ Environmental Macedonian Conference, Thessaloniki, March 2008.

King E.A., Murphy E. and MacNabola A. (2009), Reducing pedestrian exposure to environmental pollutants: A combined noise exposure and air quality analysis approach, Transportation Research Part D: Transport and Environment, 14(5), 309-316.

Meteothess web site. URL: http://www.meteothes.gr/index.php?lang=en.0 (Last visited April 2013).

Moussiopoulos N., Vlachokostas Ch., Tsilingiridis G., Douros I., Hourdakis E., Naneris C. and Sidiropoulos C. (2009), Air quality status in greater Thessaloniki Area and the emission reductions needed for attaining the EU air quality legislation, Sci. Total Environ., 407, 1268-1285.

Moussiopoulos N., Achillas Ch., Vlachokostas Ch., Spyridi D., and Nikolaou K., (2010), Environmental, social and economic information management for the evaluation of sustainability in urban areas: A system of indicators for Thessaloniki, Greece, Cities, 27, 377-384.

Murphy E., King E.A. and Rice H.J. (2009), Estimating human exposure to transport noise in central Dublin, Ireland, Environ. Int., 35, 298-302.

Organisation for the Master Plan and Environmental Protection of Thessaloniki (ORTh), (2008), System of indicators for the environment and sustainable development of the Greater Thessaloniki Area. Hellenic Ministry of the Environment, Physical Planning \& PublicWorks, Final report Greece: Thessaloniki; 2008 (in Greek).

Pope C.A., Brook R.D., Burnett R.T. and Dockery W.D. (2011), How is cardiovascular disease mortality risk affected by duration and intensity of fine particulate matter exposure? An integration of the epidemiologic evidence, Air Qual Atmos Health, 4, 5-14.

Tzekakis E., Nikolaou K. and Vasileiadis V. (2005), Noise observatory in the city of Thessaloniki, Greece. Proceedings of the $2^{\text {nd }}$ Macedonian Environmental Conference, Thessaloniki, Greece, October 812, 2005. 
Vlachokostas Ch., Achillas Ch., Moussiopoulos N., Hourdakis E., Tsilingiridis G., Ntziachristos L. and Sidiropoulos C. (2009), Decision support system for the evaluation of urban air pollution control options: application for particulate pollution in Thessaloniki, Greece, Sci. Total Environ., 407, 5937-5938.

Vlachokostas Ch., Achillas Ch., Moussiopoulos N. and Banias G., (2011), Multicriteria methodological approach to confront urban air pollution, Atmos. Environ., 45, 4160-4169.

Vlachokostas Ch., Achillas Ch., Michailidou A.V. and Moussiopoulos N. (2012), Measuring combined exposure to environmental pressures in urban areas: An air quality and noise pollution assessment approach. Environ. Int., 39, 8-18.

Vlachokostas Ch., Michailidou A.V, Spyridi D., and Moussiopoulos N. (2013), Building statistical associations to forecast ethylbenzene levels in European urban traffic environments, Environ. Pollut., 177, 125-134.

WHO (World Health Organisation), 2005. Health effects of transport-related air pollution, ed. Krzyzanowski M., Kuna-Dibbert B. and Schneider J. 